\title{
QUANDO O BRINQUEDO É O VIDEOGAME: REFLEXÕES SOBRE BRINCAR E JOGAR NA CONTEMPORANEIDADE
}

\section{CUANDO EL JUGUETE ES EL VIDEOJUEGO: REFLEXIONES SOBRE JUGAR EN LA CONTEMPORANEIDAD}

\author{
LOUREIRO, Carla Cristiane \\ carlacrisloureiro@gmail.com \\ Colégio de Aplicação da Universidade Federal de Santa Catarida \\ MENDES, Geovana Mendonça Lunardi \\ geolunardi@gmail.com \\ UDESC- Universidade Estadual de Santa Catarina
}

\begin{abstract}
RESUMO Este artigo busca avançar nas reflexões sobre as relações entre crianças e videogame, visibilizando as falas e as ações das crianças sobre como se constitui a brincadeira com esse brinquedo. Para captar como as crianças atribuem sentidos à brincadeira utilizamos algumas ferramentas da pesquisa etnográfica. Nas análises, situamos os conhecimentos das crianças entre as culturas para a infância e culturas da infância. Percebemos que, para as crianças, a diversão é o princípio que caracteriza o brincar, mas, por outro lado, muitas negam que jogar videogame seja brincar, justificado por uma "não realidade" intrínseca nos videogames. Nesse sentido, as crianças parecem mostrar-nos muito mais uma dificuldade dos adultos em compreender os novos aspectos dessa cultura lúdica digital.
\end{abstract}

Palavras-Chave: Cultura lúdica. Infância. Videogame.

RESUMEN Este artículo busca avanzar en las reflexiones sobre las relaciones entre los niños y el videojuego, dando visibilidad a los discursos y acciones de los niños sobre cómo es jugar con este juguete. Para captar cómo los niños atribuyen sentidos al juego utilizamos algunas herramientas de investigación etnográfica. En los análisis, situamos los conocimientos de los niños entre las culturas para la infancia y las culturas de la infancia. Nos damos cuenta que, para los niños, la diversión es el principio que caracteriza el jugar, pero, por otro lado, muchos niegan que jugar a videojuegos sea un jugar, justificado por una "no realidad" inherente a los videojuegos. En este sentido, los niños parecen mostrarnos mucho más una dificultad que tienen los adultos para comprender los nuevos aspectos de esa cultura lúdica digital.

Palabras clave: Cultura lúdica. Infancia. Videojuego.

\section{INTRODUÇÃO}

A relação entre criança e cultura faz parte da agenda de diferentes campos disciplinares envolvidos com os estudos da infância. Esse acúmulo de pesquisas 


\section{Atos de Pesquisa em Educação - ISSN 1809-0354 \\ Blumenau, v. 12, n.3, p.828-853, set./dez. 2017 DOI: http://dx.doi.org/10.7867/1809-0354.2017v12n3p828-853}

possibilita compreender a afirmação de que a criança participa da cultura de forma ativa. Nesse sentido, pode-se sinteticamente afirmar que as crianças nascem inseridas em uma cultura, ressignificam-na e recriam-na com os instrumentos dados por essa mesma cultura. Em sua ação, as crianças não só imitam o que está instituído, elas também o criticam e o recriam.

Nessa mesma direção, os estudos sobre as relações entre crianças e tecnologia apontam que o advento das tecnologias digitais tem afetado os modos de produção e de circulação da cultura, estabelecendo novas formas de subjetividade e novos modos de sociabilidade em que podem se potencializar maior participação dos sujeitos e, nesse caso, também das crianças (PEREIRA, 2013).

As crianças como produtoras de cultura têm ampliado o seu repertório cultural no uso e nas relações com as tecnologias, mais contemporaneamente as tecnologias digitais. A partir dessa realidade, busca-se, neste artigo, avançar nas reflexões sobre as relações entre crianças e videogame, visibilizando suas falas e ações sobre como se constitui a brincadeira com esse brinquedo contemporâneo. Ao tratar dessas relações, que são parte da vida de muitas crianças, fala-se, consequentemente, das transformações atuais e das marcas que essas transformações projetam na infância contemporânea.

A reflexão aqui apresentada compõe 0 conjunto de pesquisas do Observatório "Tablets, computadores e laptops" desenvolvido no grupo de pesquisa Observatório de Práticas Escolares, e, especificamente, resulta de uma investigação ${ }^{1} \mathrm{em}$ andamento que busca compreender como se constitui o brincar com videogames, identificando e problematizando os impactos na cultura lúdica infantil e nas ideias de infância contemporânea. Tal pesquisa vem sendo realizada no Laboratório de Brinquedos do Colégio de Aplicação (LABRINCA), uma brinquedoteca escolar e universitária, com seu público composto, prioritariamente, pelas crianças do Colégio de Aplicação da Universidade Federal de Santa Catarina (CA/UFSC).

\footnotetext{
${ }^{1}$ Parte dos resultados aqui apresentados são decorrentes da pesquisa de Doutoramento em andamento desenvolvida no PPGE, na linha de pesquisa Educação, Comunicação e Tecnologia da Universidade do Estado de Santa Catarina (UDESC).
} 


\section{Atos de Pesquisa em Educação - ISSN 1809-0354 \\ Blumenau, v. 12, n.3, p.828-853, set./dez. 2017 \\ DOI: http://dx.doi.org/10.7867/1809-0354.2017v12n3p828-853}

No âmbito deste artigo, apresentamos os resultados da pesquisa em quatro seções. Inicialmente, apresentamos o LABRINCA, campo da pesquisa para, em seguida, realizarmos uma discussão sobre o brinquedo e a brincadeira na contemporaneidade. Na penúltima seção, apresentamos as falas das crianças e buscamos compreender essas falas imbricadas entre as culturas produzidas e dirigidas pelos adultos para as crianças (do mercado e a escolar) e culturas construídas nas interações entre elas no espaço de uma brinquedoteca escolar. Por fim, apresentamos, ainda que de maneira resumida, alguns eixos-chave da análise empreendida.

É nesse contexto que pretendemos contribuir para dar visibilidade em como as crianças têm compreendido a sua relação com os videogames.

\section{E LÁ BRINCA.... O ESPAÇO DA PESQUISA E AS CRIANÇAS DO COLÉGIO DE APLICAÇÃO DA UFSC}

Compreender os contextos em que vivem as crianças envolvidas em uma pesquisa assume relevância, uma vez que é no contexto que fazemos a observação da sua ação com seus pares e com os adultos em suas atividades reais e cotidianas. Compreendemos que tais contextos nunca são neutros, uma vez que são marcados por um conjunto de situações que permitem, cerceiam, constrangem ou até proíbem a ação dos indivíduos.

No caso da pesquisa com crianças, situá-las no contexto é importante, pois, se não o fizermos, corremos o risco de que o "[...] nosso conhecimento sobre as crianças continuará a ser gravemente limitado" (GRAUE; WALSH, 2003, p. 21). Não apenas continuaremos a fabricá-las sempre como uma representação dos adultos, ou, pior ainda, iremos elaborá-las sempre como anverso da vida adulta. Nesse sentido, o estudo dos contextos de ação das crianças implica na adoção de metodologias interpretativas, em que acompanhamos suas ações sistematicamente nos contextos locais, sejam eles a casa, a escola, a brinquedoteca, e até em seus tempos livres, sempre atentos as suas "particularidades concretas" e registrando-as exaustivamente (GRAUE; WALSH, 2003). 


\author{
Atos de Pesquisa em Educação - ISSN 1809-0354 \\ Blumenau, v. 12, n.3, p.828-853, set./dez. 2017 \\ DOI: http://dx.doi.org/10.7867/1809-0354.2017v12n3p828-853
}

\begin{abstract}
O contexto é mais do que um mero cenário que pode ir mudando sucessivamente - ele faz parte do retrato, emprestando vida à imagem retratada pelo investigador. Um contexto é um espaço e um tempo cultural e historicamente situado, um aqui e agora específico. É um elo [...] entre as categorias macro e microssociais. O contexto é o mundo aprendido através da interação e o quadro de interação mais imediato para os atores mutuamente envolvidos. (GRAUE; WALSH, 2003, p. 25).
\end{abstract}

Em nossa pesquisa, o contexto é fundamental, visto que observamos a ação das crianças em uma brinquedoteca que se situa em uma escola, instituição esta que historicamente definiu que:

O aluno tem por ofício, de tomar a forma (no sentido de se deixar formatar), adquirir a cultura escolar - deixando de lado, entre parêntesis ou de modo definitivo, a sua cultura de origem, quando incompatível com a cultura escolar, ou a cultura gerada e reproduzida nas relações com os seus pares: as culturas da infância - e ajustar-se à disciplina do corpo e da mente induzida pelas regras e pela hierarquia dos estabelecimentos de ensino que frequenta. (SARMENTO, 2011, p. 589).

Além disso, segundo pesquisa realizada por Peters (2014) em 53 brinquedotecas brasileiras, somente 14 afirmam disponibilizar jogos eletrônicos para seus usuários, e nenhuma delas é uma brinquedoteca escolar.

O CA/UFSC é uma instituição de atendimento à Educação Básica, vinculada ao Centro de Ciências da Educação (CED) da Universidade Federal de Santa Catarina (UFSC) e possui recursos para desenvolver práticas e produzir conhecimentos com vistas à qualidade de ensino, pesquisa e extensão. Nesta instituição, foi inaugurado, em 2003, o LABRINCA (Laboratório de Brinquedos do Colégio de Aplicação - UFSC), uma brinquedoteca que objetiva garantir a toda comunidade escolar o acesso a uma variedade de jogos e de brincadeiras, propiciando a livre expressão e a experimentação da cultura lúdica infantil.

O LABRINCA constituiu-se, desde a sua criação, como um projeto interdisciplinar que busca agregar professores e estudantes dos cursos de Pedagogia, Educação Física, Biblioteconomia, Psicologia e Arquitetura, entre outros. Tem como princípio integrar mais o conhecimento sobre infância/ludicidade trabalhado nas diferentes disciplinas dos vários cursos de formação inicial dos 


\section{Atos de Pesquisa em Educação - ISSN 1809-0354 \\ Blumenau, v. 12, n.3, p.828-853, set./dez. 2017 DOI: http://dx.doi.org/10.7867/1809-0354.2017v12n3p828-853}

estudantes e, consequentemente, incrementar a produção e a divulgação científicas sobre o tema.

A forma de entrada no CA/UFSC acontece por meio de sorteio, e crianças moradoras de diferentes locais da Região da Grande Florianópolis fazem parte do seu universo, o que resulta em um corpo discente composto por diferentes segmentos sociais e econômicos, assim como por variados registros culturais. Pensando na heterogeneidade das experiências dessas crianças, o LABRINCA procura garantir o acesso a brinquedos, jogos e brincadeiras não disponíveis a várias crianças da escola, inclusive aqueles de difícil acesso, tais como brinquedos para crianças com histórico de deficiência, não manufaturados, tradicionais. A partir de 2015, foram adicionados ao acervo os videogames, por meio do projeto de pesquisa "Jogos eletrônicos e brinquedoteca escolar: uma relação possível?" . É justamente pensando na riqueza das trocas de experiências possibilitadas por essas condições de heterogeneidade e de diversidade que se busca, também, favorecer a troca de repertório lúdico entre as crianças.

$\mathrm{O}$ atendimento aos estudantes do CA/UFSC no LABRINCA acontece no período regular de aula e/ou no período oposto, articulado às atividades realizadas no contraturno. Cada grupo de alunos cujo professor deseja frequentar o LABRINCA permanece um tempo relativo a uma ou duas aulas de 45 minutos. Os professores permanecem junto a suas turmas para, dessa forma, qualificar o brincar, propondo alternativas de jogos e de brincadeiras nos diversos cantos temáticos, além de mediar as relações entre as crianças, sem necessariamente direcionar as atividades, mas enriquecendo-as e potencializando-as.

A brinquedoteca possui forma retangular de aproximadamente $50 \mathrm{~m}^{2}$. Para fins de observação da pesquisa, o LABRINCA foi dividido em três áreas, a saber: Área 1- Espaço dos jogos: a) Jogos sociais e didáticos, b) Jogos motores; Área 2 Espaço da Imaginação: a) Fantasias/circo, b) Brinquedos de reprodução do mundo (carcaças, casinhas, miniaturas, carrinhos, bonecas); Área 3 - Espaço dos Jogos

\footnotetext{
${ }^{2}$ O projeto de pesquisa "Jogos eletrônicos e brinquedoteca escolar: uma relação possível?", do qual uma das pesquisadoras participa, busca "compreender as múltiplas relações que podem ser estabelecidas entre uma brinquedoteca escolar e os jogos eletrônicos".
} 


\section{Atos de Pesquisa em Educação - ISSN 1809-0354 \\ Blumenau, v. 12, n.3, p.828-853, set./dez. 2017 DOI: http://dx.doi.org/10.7867/1809-0354.2017v12n3p828-853}

eletrônicos: a) Jogos eletrônicos, b) Jogos/Brinquedos relacionados com jogos eletrônicos.

Nesse espaço, em março de 2015, iniciamos o mergulho no campo para a pesquisa de Doutorado com um período de observação participante, acompanhando todas as turmas dos Anos inicias ${ }^{3}$ que frequentavam a brinquedoteca. Em um diário de campo, foram registradas as primeiras impressões quanto à utilização do espaço, com especial atenção aos usos e às interações das crianças com os videogames. Também foram realizados registros fílmicos e fotográficos, entrevistas e grupos focais ${ }^{4}$.

Após esse período inicial de observação, definimos focar nossa atenção em duas turmas, uma do $1^{\circ}$ ano e outra do $3^{\circ}$ ano. Tal escolha foi motivada, principalmente, pelos seguintes fatores: consideramos que um grupo de trabalho menor, em que seja possível estabelecer uma relação de proximidade e intimidade, atenderia melhor aos objetivos da pesquisa; observar uma turma de $1^{\circ}$ ano, que ainda não conhecia a brinquedoteca e até mesmo a escola (pois ingressaram em fevereiro de 2015), e uma turma que já conhecia esses espaços, no caso o $3^{\circ}$ ano, o qual poderia fornecer olhares diferentes sobre a inserção dos videogames na escola. As turmas de $4^{\circ}$ e $5^{\circ}$ ano foram descartadas para a pesquisa, pois sua frequência de ida à brinquedoteca não era semanal.

O grupo de crianças do $1^{\circ}$ ano era constituído por 20 crianças na faixa dos cinco aos sete anos, sendo 12 meninas e oito meninos. Todas já haviam frequentado instituições de Educação Infantil, mas o CA/UFSC era uma novidade para todas. A turma do $3^{\circ}$ ano contava com 25 crianças, nove meninas e 16 meninos, com idades entre oito e nove anos, a maioria delas já estava no seu terceiro ano na escola. As duas turmas frequentavam a escola no período

\footnotetext{
${ }^{3} \mathrm{Um}$ total de quinze turmas constituem os Anos Inicias do CA/UFSC, sendo três turmas de cada ano $\left(1^{\circ}\right.$ ao $5^{\circ}$ ano). As turmas de $1^{\circ}$ ano possuem vinte crianças e as demais vinte cinco crianças em cada turma.

${ }^{4}$ O material empírico citado compõe o conjunto de dados a serem analisados na pesquisa de Doutorado já citada. Neste artigo, utilizamos apenas as entrevistas e algunas anotações do diário de campo.
} 


\section{Atos de Pesquisa em Educação - ISSN 1809-0354 \\ Blumenau, v. 12, n.3, p.828-853, set./dez. 2017 DOI: http://dx.doi.org/10.7867/1809-0354.2017v12n3p828-853}

vespertino e iam regularmente ao espaço da brinquedoteca uma vez por semana no espaço de duas aulas (por volta de uma hora e trinta minutos).

Durante o período no campo, realizamos uma entrevista dividida em duas partes. Na primeira, as crianças responderam sobre os equipamentos para jogar que possuem em casa e seus usos. Na segunda, elas falaram sobre a experiência de jogar videogame na brinquedoteca. As entrevistas foram aplicadas individualmente e, em função de a maioria das crianças do $1^{\circ}$ ano não dominarem a escrita e a leitura, a pesquisadora optou por fazer o registro de todas as respostas em um formulário online. As respostas das questões abertas foram lidas para as crianças que não sabiam ler, a fim de garantir o que elas tinham respondido estava registrado da forma correta. As crianças que já sabiam ler iam acompanhando a digitação das respostas e intervindo se achavam que não era bem isso que queriam dizer.

A partir dessa entrevista, pudemos saber que somente quatro crianças do $1^{\circ}$ ano não possuíam acesso à internet nas suas casas, enquanto que, no $3^{\circ}$ ano, apenas uma não tinha acesso. Mesmo as crianças que não tinham acesso à internet em casa possuíam algum equipamento de tecnologia digital, com destaque para computadores e notebooks e, em segundo lugar, os tablets. Os consoles de videogame têm pouca presença nas casas de todas as crianças; somente 14 crianças afirmaram possuir tal equipamento.

Outro dado que se destaca é que apenas três crianças, das 45 , disseram nunca jogar nenhum tipo de jogo eletrônico em casa; duas delas afirmaram que os equipamentos que possuíam "não têm jogos" e uma explicou que não jogava, pois "só meu irmão fica jogando". Portanto, os dados apontam que o videogame faz parte do repertório cultural disponibilizado para a maioria das crianças; desse modo, compreender sua relação com ele é um dos objetivos da investigação aqui apresentada.

Além disso, um dos aspectos interessantes a destacarmos no que diz respeito à análise das relações das crianças com os videogames no LABRINCA também se ancora na própria presença do videogame dentro da escola. Brailovsky (2012), ao falar dos objetos que adentram no universo escolar, utiliza uma trilogia 


\section{Atos de Pesquisa em Educação - ISSN 1809-0354 \\ Blumenau, v. 12, n.3, p.828-853, set./dez. 2017 \\ DOI: http://dx.doi.org/10.7867/1809-0354.2017v12n3p828-853}

em que apresenta três categorias bastante interessantes para entender a relação cotidiana da escola com os objetos culturais, são elas: objetos oficiais, objetos em disputa e objetos ilícitos.

Os objetos oficiais são aqueles produzidos para a escola ou incorporados à atividade do ensino e aprendizagem, que inclusive já detém um manual de instruções vinculadas ao ensino. Os objetos em disputa são aqueles não pensados para a escola, estão no cotidiano da vida social, e que, ainda, têm uma apropriação duvidosa no ambiente escolar. A televisão ocupou esse espaço, o computador já ocupou esse espaço e os videogames e os celulares ainda estão nele. Já os objetos ilícitos são aqueles que, ainda que adentrem, não são aceitos no cotidiano escolar, como revistas pornográficas, armas e tantos outros.

Desse modo, é interessante perceber como um espaço como uma brinquedoteca cria um "lugar oficial" para este objeto em disputa, o videogame, e como nesse universo as crianças vão se relacionar com ele.

\section{AFINAL, O QUE É BRINCAR? O VIDEOGAME É UM BRINQUEDO?}

Para Benjamin (2002), não é o conteúdo do brinquedo que define a brincadeira da criança, mas, ao contrário, é a criança, ao brincar, que transforma em brinquedo qualquer objeto de que possa dispor: pedrinhas e mato viram comida, pedaços de madeira viram avião, panela vira chapéu ou vassouras viram cavalos.

Sem desconsiderar essa capacidade imaginativa na ação do brincar, trataremos, neste artigo, de um tipo particular de brinquedo - brinquedo como objeto que os adultos produzem e oferecem às crianças com a finalidade de promover suas brincadeiras, considerando que, na modernidade, os brinquedos consolidaramse em nossa cultura como objetos representativos da infância.

Compreender o mundo dos brinquedos permite destacar as mudanças que esse objeto vem sofrendo nas últimas décadas, pois as mudanças não estão apenas assentadas nos objetos, mas, principalmente, nas culturas infantis e no lugar da infância na sociedade. 


\author{
Atos de Pesquisa em Educação - ISSN 1809-0354 \\ Blumenau, v. 12, n.3, p.828-853, set./dez. 2017 \\ DOI: http://dx.doi.org/10.7867/1809-0354.2017v12n3p828-853
}

\begin{abstract}
Para as crianças existe um espaço público no qual elas elaboram uma cultura comum, lugar de apropriação e de circulação de elementos que vem de fontes bem diferentes: do espaço particular e do discurso dos pais, do espaço escolar e da intervenção dos educadores, do espaço comercial e das propostas dos fabricantes, do espaço midiático e dos espetáculos aí mostrados. Nessa rede complexa, crianças produzem sua cultura na relação com o grupo. (BROUGÈRE, 2004, p. 330).
\end{abstract}

Para início do debate, uma questão importante merece nossa atenção. Ela se refere à diferenciação que existe na língua portuguesa entre os substantivos "jogo e brincadeira" e os verbos "jogar e brincar". Esse aspecto dificulta, por vezes, a utilização desses termos de nossa cultura a partir de referenciais teóricos e de conceitos em outras línguas. Esses conceitos estão impregnados de significados e nuances que, às vezes, implicam na mudança de todo sentido proposto por um autor. Tratando-se do valor social que o jogo e a brincadeira têm e tiveram na história, essas diferenciações acabam por refletir como as diferenças linguísticas e culturais construíram a forma como compreendemos essas categorias.

$\mathrm{Na}$ língua portuguesa, há uma diferenciação entre os verbos brincar e jogar; o que implica uma diferenciação na sua ação. No Brasil, o ato de brincar normalmente é compreendido como as ações lúdicas e imaginativas das crianças por meio do uso ou não de objetos como os brinquedos. Jogar é utilizado quando essas ações são mediadas por um conjunto de regras definidas a priori e pelo próprio objeto (no caso, o jogo). Essas características transformam o jogo e o jogar mais valorizados por serem objetivos, identificáveis e planificáveis, em especial quando recebem a adjetivação de educativos. O uso corrente, na literatura, dos verbos jogar e brincar como sinônimos também não auxilia muito na especificidade desses termos.

Para além das questões semânticas, para pensarmos na definição do videogame como brinquedo, é fundamental buscar autores que tratem as relações dos conceitos teóricos de jogo e brincadeira com as crianças.

O brinquedo também é tradicionalmente considerado como um suporte para as ações lúdicas da criança, trazendo representações acionadas pela memória e pela imaginação. Ele tem uma "[...] dimensão material, cultural e técnica que serve como suporte para a brincadeira acontecer, e é compreendido como estimulante material para fazer fluir o imaginário infantil" (KISHIMOTO, 1999, p. 111). 


\section{Atos de Pesquisa em Educação - ISSN 1809-0354 \\ Blumenau, v. 12, n.3, p.828-853, set./dez. 2017 DOI: http://dx.doi.org/10.7867/1809-0354.2017v12n3p828-853}

brinquedo proporciona à criança uma experiência que lhe permite dar sentido aos elementos da cultura contidos no objeto, pois ela não recebe o brinquedo passivamente, ela interpreta-o, desvenda-o, pois é necessário compreender sua lógica para brincar.

O brinquedo não é toda a experiência infantil, mas um objeto entre outros, um elemento, e, sem dúvida, não o mais importante, da experiência complexa e multiforme que vivem todas as crianças. [...]. Qualquer que seja a sua importância, o brinquedo está inserido numa experiência complexa nunca isolada, acompanhada de discursos diversos, que desembocam em ações heterogêneas. (BROUGËRE, 2004, p. 250).

Já a brincadeira é compreendida como a ação que a criança realiza ao concretizar e/ou recriar suas regras, com uso ou não de objetos ao embarcar na ação lúdica. Essa ação só tem valor e significado em um tempo e em um espaço determinados e a partir da decisão de quem está brincando.

Para Brougère $(1998,2002)$, a brincadeira não é qualquer manipulação de brinquedos, mas sim uma atividade com características particulares. Para o autor, se tivesse que reunir alguns critérios para dar uma definição sobre a brincadeira, esta seria: uma atividade de segundo grau constituída de decisões, com regras, incerta quanto ao seu fim, e frívola, pois é limitada nas suas consequências.

A brincadeira como uma atividade de segundo grau diz respeito à utilização de uma metalinguagem entre os participantes quando estes trocam sinais verbais e não verbais veiculando a mensagem: "isso aqui é um faz de conta". Essa metalinguagem, em forma de códigos, é o que permite diferenciar, por exemplo, uma briga de uma brincadeira de luta, na qual, muitas vezes, a diferença só é perceptível para os jogadores.

A noção de decisão refere-se à possibilidade de participar ou não da atividade, assim como nela permanecer ou não. Dessa forma, para Brougère, "brincar/jogar é decidir", o que, por vezes, implica uma sucessão de decisões também com relação aos outros e ao que eles propõem. Tudo pode ser brincadeira, desde que os jogadores assim decidam.

Mesmo que pareça contraditório, é por meio das regras que há lugar para a liberdade acontecer na brincadeira, pois a existência das regras é que permite 


\section{Atos de Pesquisa em Educação - ISSN 1809-0354 \\ Blumenau, v. 12, n.3, p.828-853, set./dez. 2017 DOI: http://dx.doi.org/10.7867/1809-0354.2017v12n3p828-853}

estabelecer os parâmetros e os limites para a ação de quem brinca. Essa regra, porém, não tem força de lei, mas está ligada a um acordo sobre como fazer, uma vez que as regras são negociáveis e modificáveis pelas crianças em diferentes situações. A famosa música "João e Maria", de Chico Buarque, por exemplo, segundo o compositor, foi composta quando ele viu uma situação de brincadeira das filhas. A cada nova ação, elas colocavam uma nova regra: "Agora eu era herói, e o meu cavalo só falava inglês", representa, poeticamente, isso.

A frivolidade da brincadeira é uma consequência da sua dimensão de atividade de segundo grau, ligada à decisão, a qual é pensada como uma ausência relativa de consequências, uma vez que é acionada pela ação do próprio sujeito e não pelos outros. Uma consequência da frivolidade é que não sejam definidas a priori as finalidades externas da brincadeira, sob o risco de sua descaracterização. $\mathrm{E}$, finalmente, a incerteza do que vai acontecer durante o processo da brincadeira, dos seus resultados e de como ela terminará.

De forma geral, os princípios propostos pelos autores embasam de forma significativa questões fundamentais para este artigo. Contudo, ao pensar na especificidade do brincar das crianças com os videogames, é necessário também compreender a cultura lúdica, pois ao utilizá-la para brincar a criança tem acesso aos elementos conhecidos ou desconhecidos dessa cultura. Ainda que não tenhamos espaço nos limites deste texto, vale a pena destacar que nossa compreensão sobre cultura lúdica e da infância se ancora nas perspectivas críticas de cultura, especialmente na compreensão de cultura como prática ordinária defendida por Raymond Willians (1992) e também nos estudos de cultura de Néstor Canclini (1997), que buscam desmontar hierarquizações entre cultura popular e cultura erudita.

Toma-se aqui o termo cultura lúdica para designar o conjunto de códigos e sentidos que permitem tornar a brincadeira possível, não se limitando a estruturas dos jogos com regras. A cultura lúdica configura-se uma combinação complexa entre a observação da realidade social, os hábitos de brincar e os suportes materiais disponíveis e que, em certa medida, toma para si elementos da cultura das crianças para adicionar ao jogo (BROUGĖRE, 1998). 


\section{Atos de Pesquisa em Educação - ISSN 1809-0354 \\ Blumenau, v. 12, n.3, p.828-853, set./dez. 2017 \\ DOI: http://dx.doi.org/10.7867/1809-0354.2017v12n3p828-853}

Assim, parte-se do princípio de que as crianças constroem a cultura lúdica brincando, ou seja, precisam partilhá-la. Essas crianças inserem-se igualmente em um sistema de significações construído a partir das características culturais do coletivo ao qual elas pertencem, e que Ihes permite atribuir sentidos para o seu brincar. A necessidade de compartilhar para brincar - que implica o fato de aprender ou já conhecer a brincadeira - propicia o estabelecimento de trocas sociais, o sentimento de pertencimento e a criação de vínculos afetivos, fundamentais no seu processo de subjetivação.

Partindo do conceito de cultura lúdica, intenta-se compreender como os videogames têm enriquecido ou modificado essa cultura. Nesse sentido, há de se considerar que os videogames se constituem como elementos de forte apelo para as crianças devido a estratégias globais de propaganda que as alcançam por intermédio da TV, do computador e de toda gama de dispositivos eletrônicos a que elas têm acesso ${ }^{5}$.

Nessa perspectiva, compreendemos os videogames necessariamente como também um brinquedo. Os videogames podem ser entendidos como

[...] un tipo de interfaz lúdica en la que intervienen diseñadores, jugadores y dispositivos tecnológicos. En tanto lúdica, la interfaz que proponen los videojuegos tiene una trama narrativa que la sustenta y que los jugadores recrean y alteran dependiendo de las modalidades de juego y los tipos de usuarios. (FAJARDO, 2015, p. 21).

Diante disso, o próprio autor complementa dizendo que, nessa direção, podemos compreender, considerando a dimensão lúdica, o videogame como uma prática social e, como tal, cultural.

[...] una práctica social, inmersa en unas condiciones históricas, sociales y materiales determinadas, esto es, una práctica que se da en contextos específicos (Mäyrä, 2008) y por tanto responde a dinámicas globales y locales de la esfera social e íntima de los usuarios. Como práctica es inseparable de los sentidos que le asignan las personas involucradas en ella

\footnotetext{
${ }^{5}$ Para os objetivos e limites deste artigo não é possível aprofundar a discussão sobre os aspectos culturais da "globalização" e homogeneização da infância pelo consumo. Para mais discussões ver: Steinberg e Kincheloe (2001), Buckingham $(2007,2013)$. Os primeiros criticam a relação da criança com a "sociedade de consumo"; o último aponta o caráter "conservador, paternalista e essencialista da infância".
} 


\section{Atos de Pesquisa em Educação - ISSN 1809-0354 \\ Blumenau, v. 12, n.3, p.828-853, set./dez. 2017 \\ DOI: http://dx.doi.org/10.7867/1809-0354.2017v12n3p828-853}

y dicho proceso se realiza siempre en contextos cotidianos (uno de ellos la escuela) y en relación con los otros que rodean al sujeto (Winocur, 2009). (FAJARDO, 2015, p. 21).

Desse modo, compreendemos que as crianças são atores sociais que participam ativamente na construção de culturas infantis autônomas (SIROTA, 2001; BROUGĖRE, 2002), e constroem formas culturais radicadas e desenvolvidas historicamente em "[...] modos específicos de comunicação intrageracional e intergeracional" (SARMENTO, 2002, p. 21).

Nesse sentido, as culturas da infância não são meras reprodutoras das culturas adultas; muito menos se configuram como representações menores ou imperfeitas do mundo dos adultos. A diferença entre as duas culturas deriva do modo específico como as crianças simbolizam o mundo, especialmente por meio da brincadeira e da fantasia. Nesse sentido, aponta-se para a centralidade que as culturas lúdicas têm para a construção da ideia de infância no ocidente, visto que "[...] a natureza interactiva do brincar constitui-se como um dos primeiros elementos fundacionais das culturas da infância" (SARMENTO, 2004, p. 16).

A partir da compreensão da participação das crianças na construção do seu ser social e cultural e da reprodução interpretativa (CORSARO, 2011), apresentamos as vozes das crianças para buscar uma aproximação de como elas têm compreendido sua relação com os videogames. Somente com uma análise do uso efetivo que a criança faz do brinquedo, de que forma ela dá sentido a ele ao inseri-lo (ou não) em uma brincadeira, é que podemos compreender toda complexidade da relação das crianças com cada brinquedo.

\section{JOGAR OU BRINCAR: AS CRIANÇAS NA BRINQUEDOTECA}

"Videogame é mesma coisa que brincar, videogame também é um brinquedo, mas ficamos sentados para jogar." (Marta, seis anos). 


\section{Atos de Pesquisa em Educação - ISSN 1809-0354 \\ Blumenau, v. 12, n.3, p.828-853, set./dez. 2017 DOI: http://dx.doi.org/10.7867/1809-0354.2017v12n3p828-853}

A fala de Marta $^{6}$ reflete uma síntese do que as crianças ouvidas nesta pesquisa pensam sobre os videogames, - sim, as crianças estão brincando quando estão frente aos seus videogames -, embora, segundo elas mesmas, há algumas diferenças importantes quando comparadas a outros tipos de brincadeiras.

$\mathrm{Na}$ entrevista produzida junto às crianças, havia a seguinte pergunta: Você acha que quando as crianças estão jogando videogame elas estão brincando? As respostas em termos quantitativos apontam que as crianças maiores (do $3^{\circ}$ ano) parecem fazer uma distinção entre brincar e jogar videogame, 13 das 25 crianças acham que jogar videogame não é brincar, nove acham que é, e três afirmam não saber. Já o grupo de crianças do $1^{\circ}$ ano não parece ver grandes diferenças entre essas atividades, 12 afirmam que jogar videogame é brincar, sete acreditam que não é, e, apenas uma não soube responder. Ao juntarmos as respostas dos dois grupos, percebemos que praticamente metade das crianças acredita que jogar videogame é brincar e metade acredita que não, e, para avançarmos nas análises sobre a questão, as justificativas para suas respostas dão-nos algumas pistas.

Analisando inicialmente as justificativas das crianças que consideram que jogar não é brincar, podemos destacar três "motivos" principais que distanciam o videogame de uma brincadeira: "não usamos o corpo, só mexemos com o controle", "precisa de um equipamento" e "videogame não é vida real".

Críticas do senso comum aos videogames parecem convergir com as observações das crianças sobre o fato de que confinadas em suas casas e quartos, passando muito tempo na frente da TV, computador ou quaisquer outros dispositivos móveis que tenham, as crianças estão se movimentando menos. Como consequência disso, frequentemente encontramos discursos, inclusive veiculados nas mídias, que tais hábitos das crianças "de hoje" contribuem para o isolamento social, obesidade, sedentarismo, além de uma diminuição de experiências significativas e "reais" com outras crianças. Tais discursos e as respostas das crianças conflitam com as observações feitas em campo:

\footnotetext{
${ }^{6}$ Todos os nomes das crianças são fictícios, conforme descreve o Termo de consentimento livre e esclarecido assinado por elas e por seus responsáveis, tal como indicado pelo Parecer Consubstanciado do CEP, número 128.511, de 22/10/2012.
} 


\author{
Atos de Pesquisa em Educação - ISSN 1809-0354 \\ Blumenau, v. 12, n.3, p.828-853, set./dez. 2017 \\ DOI: http://dx.doi.org/10.7867/1809-0354.2017v12n3p828-853
}

\begin{abstract}
Quatro meninos jogam Mario Kart, o joystick é em forma de volante, para cada curva necessária na tela, os meninos mexem o corpo todo, para a direita... para a esquerda. Muitas vezes, o corpo é jogado para trás, fazendo um barulhão quando batem com as costas no pufe e, em geral, esse movimento é uma reação à alguma "barbeiragem" do seu carrinho na tela. Eles também vão "narrando" o jogo: "vai, corre!!"; "come a vontade a plantinha"; "é isso mesmo", onomatopeias também fazem parte da narração. No outro console, algumas meninas jogam Just Dance, e, algumas vezes, sem desgrudar o olho da tela e a atenção do jogo, os meninos cantam o refrão da música que as meninas dançam: "Let it go! Let it go!" Fim da corrida. Quando o resultado aparece na tela, o vencedor se levanta com o volante no alto (como um troféu) e pulando comemora: primeiro, primeiro, primeiro!!!! (Diário de campo, 26/02/2015).
\end{abstract}

Além dessa nota transcrita, os vídeos gravados no espaço da brinquedoteca têm muitas horas de crianças "mexendo no controle" e movimentando o corpo todo, e, aqui, não estamos falando apenas dos videogames com joystic ${ }^{7}$ que reagem ao movimento, mas de praticamente todos os jogos. Mesmo quando acomodadas nos pufes para jogar, as crianças estão quase sempre conversando, discutindo estratégias para jogo, ou tirando dúvidas com os colegas e, com frequência, narram o jogo em voz. Toda essa movimentação e conversa parecem necessárias para que elas lidem com a complexidade espacial das três dimensões do jogo.

Mais do que isso, para que o processo de descoberta acontecesse plenamente, para que elas conseguissem controlar o personagem da tela, ou melhor, para que elas, em meio à fantasia e às dinâmicas do jogo se transformassem no personagem da tela, não era suficiente um processo de aprendizado restrito à esfera cognitiva. O apertar de botões só parecia fazer sentido quando a criança intermediava corporalmente o que era visto na tela. O brincar, assim como o aprender, mostrava-se repleto de sinestesias.

Considerando que o contexto social das crianças de hoje tem uma configuração bem diversa daquela vivida por seus pais e que a urbanização trouxe como consequências a perda de seu espaço, no quintal da casa, na rua, no jardim e

\footnotetext{
${ }^{7}$ O joystick é o periférico de controle de um videogame. A maior parte deles é composto por múltiplos botões e alavancas que assumem diferentes funções de acordo com a proposta de cada videogame. A última geração de videogames passou a valer-se de sensores para que os jogos eletrônicos possam ser controlados por meio da captação direta do movimento humano no ambiente.
} 


\section{Atos de Pesquisa em Educação - ISSN 1809-0354 \\ Blumenau, v. 12, n.3, p.828-853, set./dez. 2017 DOI: http://dx.doi.org/10.7867/1809-0354.2017v12n3p828-853}

nas praças, a escola aparece como uma instituição importante para que as brincadeiras aconteçam. É nesse lugar que encontramos momentos destinados especialmente às brincadeiras livres, como a hora do recreio, com oferta de lugares e objetos específicos para que estas aconteçam, tais como brinquedos no pátio e parques infantis e, no caso da escola pesquisada, também uma brinquedoteca. Outro fator importante é que a escola tem se tornado o principal, senão o único, lugar onde as crianças se reúnem, criando uma relação de interação e criação cultural entre pares.

Nesse sentido, a imagem de uma criança sozinha, trancada no seu quarto por horas com seu console, permite compreender os discursos "apocalípticos" que reverberam nas mídias e incidem diretamente nas falas e nas atitudes dos pais quando o assunto são os videogames. Contudo, acompanhar as crianças interagindo em um ambiente organizado para o brincar, mesmo dentro de uma escola, pode trazer novas lentes para a questão.

\footnotetext{
"Para brincar você está com o boneco brincando de verdade, na mão. Nos jogos só estou com o controle na mão controlando os bonecos na tela. Eu também controlo quando brinco, mas com a minha mão, sem o controle." (Leandro, nove anos).

"Jogar tu não brinca, porque só usa a mão para mexer no controle, e brincar usa o corpo inteiro." (Luara, nove anos).
}

As falas de Leandro e Luara, que não acreditam que jogar videogame seja uma brincadeira, exprimem uma das características da brincadeira apontada por Brougère (2004) quando este afirma que o universo da brincadeira só pode ser construído como resultado da ação de quem brinca e só continua a existir pelo desejo de quem brinca. Portanto, a mediação do joystick parece estar tirando parte do controle da criança sobre a brincadeira, o boneco/personagem está lá, mas o fato de sua mão não o tocar para definir seus movimentos limita a percepção de sua ação. "Controlar os bonecos", muito mais do que uma ação corporal, parece ser um diálogo que as crianças estabelecem com o mundo e com os objetos por meio da brincadeira. No entanto, por que "controlar os bonecos na tela" não é compreendido com o mesmo potencial lúdico? 


\title{
Atos de Pesquisa em Educação - ISSN 1809-0354 \\ Blumenau, v. 12, n.3, p.828-853, set./dez. 2017 DOI: http://dx.doi.org/10.7867/1809-0354.2017v12n3p828-853
}

No videogame, no pátio da escola ou no seu quarto, as crianças movimentam bonecos, criam diferentes "vozes" para falar por eles, inventam histórias, confusões e desfechos. Como comandante do universo de bonecos, sejam eles de pano, de plástico ou de pixels, as crianças criam e recriam o mundo sempre que brincam. Sem desvalorizar as possibilidades que a exploração material do mundo, em que a criança envolve todo o corpo na brincadeira fora do mundo virtual, a experiência de mediação do joystick na brincadeira não parece ser um limitador para a brincadeira com o videogame, uma vez que outras atividades consideradas bastante valiosas para a educação das crianças, em especial na escola, como desenhar, pintar ou jogar jogos de tabuleiro, também não demandam grande movimentação física.

Como interação social, entendemos aqui a brincadeira como um espaço de comunicação e interpretação da realidade que vai sendo negociado passo a passo pelos pares. Segundo Brougère (1995), a criança apropria-se do universo que a rodeia para conciliá-lo com sua própria dinâmica. Essa apropriação do mundo passa por constantes adaptações, negociações, regras e modificações que, no conjunto, constituem a brincadeira. Essas adaptações são condicionadas por outro fator que engloba todas as características encontradas nas brincadeiras: a cultura.

\begin{abstract}
A brincadeira é, antes de tudo, uma confrontação com a cultura. $\mathrm{Na}$ brincadeira, a criança se relaciona com conteúdos culturais que ela reproduz e transforma, dos quais ela se apropria e lhes dá uma significação. A brincadeira é a entrada na cultura, numa cultura particular, tal como ela existe num dado momento, mas com todo seu peso histórico. (BROUGĖRE, 1994, p. 76-77).
\end{abstract}

Ao considerar a brincadeira como interação e aprendizagem entre os pares, um aspecto que deve ser superado, segundo o mesmo autor, é a definição da brincadeira como uma atividade natural da infância. Para Brougère (1994), a brincadeira deve ser situada como aprendizado cultural, pois a criança desenvolvese pela experiência social e pelas interações que estabelece com outras pessoas desde seu nascimento. A criança está situada em um determinado contexto social e seus comportamentos são influenciados por esse contexto em um processo de trocas. Assim, segundo o autor, a brincadeira, como resultado de relações interindividuais, não é inata, mas decorrente de um processo de aprendizagem. 


\section{Atos de Pesquisa em Educação - ISSN 1809-0354 \\ Blumenau, v. 12, n.3, p.828-853, set./dez. 2017 DOI: http://dx.doi.org/10.7867/1809-0354.2017v12n3p828-853}

Nessas trocas, a compreensão de que adultos e crianças estabelecem relações e têm referenciais culturais diferentes para interpretar os brinquedos e as brincadeiras pode nos ajudar a desvelar as falas das crianças sobre os videogames.

$O$ adulto faz uma leitura estética do brinquedo, interpreta no objeto sua visão de infância, visão esta impregnada, muitas vezes, de discursos românticos que afirmam que a brincadeira sem suportes é mais natural, tem maior fluidez ou de que os brinquedos são simplesmente elementos do mercado. "Sem dúvida ainda somos românticos, pois o discurso contemporâneo continua a trazer esse duplo valor, a positividade da infância na brincadeira, a negatividade de uma sofisticação que destruiria a espontaneidade infantil" (BROUGĖRE, 2004, p. 265).

Por outro lado, as crianças veem no brinquedo um objeto a ser utilizado na brincadeira, sendo sua imagem interpretada justamente para isso, mas, como objeto, a relação, que as crianças estabelecem com os brinquedos, configura-se como um processo de recriação, de interpretação e deciframento, que possibilita a atribuição de múltiplos significados aos objetos, e esse processo implicaria em conhecer, reconhecer e produzir semelhanças. Nesse sentido, a brincadeira não é apenas determinada pelo conteúdo imaginário do brinquedo ou por aquilo que os fabricantes e/ou adultos que projetaram/compraram o brinquedo definiram para a brincadeira.

$O$ brinquedo também introduz a criança para uma sociedade em que 0 contato com os objetos é permanente e até inerente ao seu próprio funcionamento quotidiano. É por meio do brinquedo que a criança constrói as suas relações de posse, de utilização, de abandono, de perda, de quebra - que, no fundo, constituem as interações que ela realizará com variados objetos por toda sua vida. Nesse sentido:

A infância é um momento de apropriação de imagens e de representações diversas que transitam por diferentes canais. As suas fontes são muitas. $O$ brinquedo é, com as suas especificidades, uma dessas fontes. (BROUGÈRE, 1995, p. 40). 


\section{Atos de Pesquisa em Educação - ISSN 1809-0354 \\ Blumenau, v. 12, n.3, p.828-853, set./dez. 2017 DOI: http://dx.doi.org/10.7867/1809-0354.2017v12n3p828-853}

Nesse processo de apropriação, ao mesmo tempo em que as crianças, por meio de suas falas, mostram suas dúvidas sobre o potencial lúdico dos videogames, as dúvidas com relação à importância do brincar nas suas vidas não aparecem:

\footnotetext{
"Porque videogame não é vida real, brincar é vida real" (Lucas, nove anos).

Porque se tu está jogando você não esta na vida real e se tu está brincando você está na vida real. (Paulo, nove anos).
}

Porque você não esta dentro do videogame, você morre e revive e na vida real não, mas eu não tenho certeza disso. (Milena, oito anos).

Ao introduzir uma oposição entre o "real" e o "não real" (que alguns poderiam chamar de virtual, mas não estamos certas de que as crianças queriam dizer isso), deixando o videogame do lado "não real", as crianças parecem ecoar os discursos sobre o uso de tecnologias endereçadas a elas. Pais, educadores e especialistas são unânimes em apontar os desafios exigidos para o enfrentamento das desigualdades de acesso à tecnologia surgida na nossa sociedade. Ao mesmo tempo, em se tratando especialmente do brincar, e, talvez, impregnado pelo discurso romântico da natureza da infância, há uma valorização do "real" contra o "virtual" (que deve ser usado de forma controlada e instrumental). Nesse cenário, as crianças devem converter-se em um "usuário racional" das tecnologias por meio de "tentativas superficiais de combinar educação e entretenimento, ou um relato festejador do potencial educativo da nova mídia" (BUCKINGHAM, 2010, p. 53).

O envolvimento das crianças com os videogames está longe de ser instrumental; elas usam o jogo para brincar e não como ferramenta para resolução de tarefas específicas. Além disso, os videogames (e os jogos eletrônicos em geral) apresentam um novo mundo para os brinquedos, apesar dos princípios básicos terem sido retirados do universo dos jogos tradicionais (jogos de corrida, luta, aventura, construção, etc.), sua aplicação é original. Distante de ser uma simples implementação de uma inovação técnica, os videogames expressam uma nova forma de brincar, especialmente por meio das possibilidades gráficas que as novas máquinas permitem. Elas expressam a primazia da imagem e da imaginação, possibilitando às crianças um mergulho em novas experiências e novas lógicas, que 


\title{
Atos de Pesquisa em Educação - ISSN 1809-0354 \\ Blumenau, v. 12, n.3, p.828-853, set./dez. 2017 \\ DOI: http://dx.doi.org/10.7867/1809-0354.2017v12n3p828-853
}

não se restringem ao "uso racional" ou ao domínio técnico, mas à própria condição lúdica do brinquedo.

\begin{abstract}
Uma nova norma se impõe: o brinquedo não é mais um objeto isolado, é acompanhado de uma história, é o centro de diversas aventuras que lhe dão consistência e uma visibilidade que não possuía antes. Mais ainda, ele ganha notoriedade e personalidade, possui um nome próprio e uma biografia. Embora cada vez mais mergulhado no imaginário, ele é mais real do que nunca: vive em outros lugares, no espaço midiático e virtual. [...] $\mathrm{O}$ brinquedo nunca foi tão realista, porque nunca foi tão marcado pelo imaginário. (BROUGĖRE, 2004, p. 332).
\end{abstract}

Nesse sentido, a posição da brincadeira no mundo "real" e do videogame no "não real", que aparece na fala das crianças, aponta para a centralidade e a seriedade que o brincar tem nas culturas da infância. Contudo, por que o videogame está no outro polo?

Em nossas observações das crianças na brinquedoteca, assim que elas começam a jogar, aparece a brincadeira narrativa, a verbalização de um faz de conta diante das imagens na tela. Além disso, as crianças trocam informações umas com as outras sobre como "passar de fase", que botão apertar para efetivar determinada ação na tela, entre outras conversas. Esses elementos revelam não algo novo, mas sim a manifestação dos eixos estruturantes das culturas da infância: a interatividade, a ludicidade, a fantasia do real e a reiteração (SARMENTO, 2004).

$A$ interatividade refere-se à forma interativa e partilhada pela qual as crianças participam e aprendem a partir dos diferentes contextos de sua vida cotidiana: a família, a escola, a comunidade, as mídias; que contribuem para formação de sua identidade pessoal e social. Essa aprendizagem tem como eixo a interação com seus pares e com os adultos e jovens com os quais elas convivem. Por meio dessa interação, as crianças têm construído sua relação com os videogames.

Na roda final, uma criança disse que tem alguns jogos de videogame que deixam as crianças mais violentas, algumas concordam, outras não. Um dos meninos diz que é por causa dos palavrões que têm nesses jogos, outros dizem que ele não sabe nada e que "nem tem palavrão no jogo". Ele discorda e diz:

- Vocês acham que não tem palavrão porque no jogo falam inglês e vocês não entendem!

Uma menina que só estava ouvindo se manifesta:

- Meu pai sempre tampa meus ouvidos para eu não ouvir o palavrão. 


\section{Atos de Pesquisa em Educação - ISSN 1809-0354 \\ Blumenau, v. 12, n.3, p.828-853, set./dez. 2017 \\ DOI: http://dx.doi.org/10.7867/1809-0354.2017v12n3p828-853}

Pergunto para ela porque ela tem esse jogo, e ela responde:

- Só meu pai joga, eu só assisto! (Diário de campo, 27/02/2015).

Essa conversa ilustra que, por vezes, essa relação situa-se em um território inexplorado e cheio de incertezas. Se considerarmos que o uso massivo de tecnologias não fazia parte da infância da maioria dos pais dessas crianças, e, em alguns casos, nem mesmo das crianças e dos jovens com os quais as crianças envolvidas na pesquisa mais convivem, podemos compreender as dúvidas nas suas falas que, na maioria das vezes, apontam para a incerteza do potencial lúdico do videogame.

A ludicidade é um traço central das culturas infantis, mesmo não sendo exclusiva das crianças, pois a atividade de brincar é uma dimensão humana. No contexto da infância, ela ocupa um lugar ampliado, sendo contínua, repetitiva e estruturadora de suas atividades individuais ou coletivas. A brincadeira e o brinquedo, com base na natureza interativa da atividade de brincar, são os principais pilares sobre os quais se fundam as culturas da infância. Se, como afirma Sarmento (2004, p. 25), "[...] as crianças brincam, continua e abnegadamente", e, "contrariamente aos adultos, entre brincar e fazer coisas sérias não há distinção". A separação indicada entre "real" e "não real" parece indicar que, quando as crianças jogam videogame, esse objeto ainda não foi apropriado, isto é, os esquemas, as estruturas de brincadeira já conhecidas e até os limites entre o que é "real" e ao "não é real" parecem estar borrados.

O uso lúdico do brinquedo é complexo, foge da dicotomia simples demais entre conformismo e desvio. Trata-se de uma produção de sentido que parte de uma cultura e ações preexistentes. Há um processo de apropriação que é sempre, por mais conforme que possa parecer, uma ação singular de produção de sentido no contexto. (BROUGĖRE, 2004, p. 267).

A fantasia do real reflete as reconstruções que as crianças fazem do real a partir do imaginário, a partir de um processo de reinterpretação das referências culturais que constituem as suas vidas cotidianas. Nesse processo, as crianças reproduzem os modelos dados pela cultura de uma forma (re) interpretativa, assim como criam ações e subversões das ordens e regras do mundo cotidiano, atuando 


\section{Atos de Pesquisa em Educação - ISSN 1809-0354 \\ Blumenau, v. 12, n.3, p.828-853, set./dez. 2017 \\ DOI: http://dx.doi.org/10.7867/1809-0354.2017v12n3p828-853}

em tempos-espaços próprios do brincar e das relações interativas dessa atividade. A fantasia e o real estão imbricados nas brincadeiras infantis, mas é preciso ter em conta que o mundo do brincar trata-se de um distanciamento da realidade que permite a reflexividade e a construção de um mundo próprio, recriado, que, apesar de manter relações com a vida cotidiana, não é vida cotidiana.

Fui observar alguns meninos que não estão jogando videogame. Sento-me próxima deles e depois de um tempo pergunto do que estão brincando.

- Estamos brincando de GTA ${ }^{8}$, fazendo uma "missão"!

Um deles me pede que filme a brincadeira, começo a filmar...

Durante a "missão", eles correm, dão tiros em inimigos imaginários e "morrem" várias vezes e, cada vez que morrem, tomam um "remédio" que faz com que "revivam". A " missão" é salvar o irmão de um deles que está preso pelo "inimigo".

Terminada a missão, eles pedem para ver a filmagem e ao assistir fazem alguns comentários:

- Olha, eu caí igual no jogo!

- A gente é bom nesse jogo!

Pergunto então como é essa história de morrer e voltar a jogar e um deles me responde:

- É irreal, como no jogo! (Diário de campo, 24/04/2015).

A narrativa de faz-de-conta construída na brincadeira descrita articula-se diretamente com as experiências que as crianças têm vivido com os videogames e, em especial, com um jogo classificado como inadequado para as crianças, mas que, de alguma forma, elas têm acesso. Talvez exatamente pelo acesso "marginal" a esse jogo (muitas crianças dizem que jogam GTA na casa de amigos ou simplesmente assistem a parentes mais velhos jogarem), a brincadeira de faz-deconta aqui se configura como a possibilidade relativa de dar significado aos sentidos projetados por esse tipo de jogo, que é muito popular e controverso.

Observar essas brincadeiras pode fornecer-nos algumas pistas para entender esses significados, mesmo assim parece que tem sido difícil para os pesquisadores

\footnotetext{
${ }^{8}$ Grand Theft Auto (GTA) é uma série de jogos de computador e videogames focada em cidades fictícias dominadas pelo crime e pelas gangues de rua. Os jogos da série são em mundo aberto e o personagem jogável (um criminoso, protagonista de um enredo repleto de atividades ilegais, como violência, tráfico de drogas, assassinato, prostituição etc.) pode cumprir missões para o progresso da história, bem como participar de ações não lineares.
} 


\section{Atos de Pesquisa em Educação - ISSN 1809-0354 \\ Blumenau, v. 12, n.3, p.828-853, set./dez. 2017 \\ DOI: http://dx.doi.org/10.7867/1809-0354.2017v12n3p828-853}

perceberem que há brincadeiras de faz-de-conta na interação das crianças com os videogames (utilizando o jogo ou quando "faz de conta" que está jogando nas suas brincadeiras), como se uma forma cultural pertencesse ao passado e à tradição, e a outra ao futuro, ambas assim impossibilitadas de coexistir.

Um último eixo apontado por Sarmento para a constituição das culturas infantis é a reiteração. O tempo da criança e do brincar é um "[...] tempo recursivo, continuamente reinvestido de novas possibilidades, um tempo sem medida, capa de ser sempre reiniciado e repetido" (SARMENTO, 2004, p. 28). Os modos de interação das crianças são marcados por práticas ritualizadas; propostas de continuidade e de repetição e também por rupturas. Nessas interações, as crianças vão se apropriando de rotinas de ação associadas às diferentes brincadeiras, aos modos de falar dos personagens assumidos, às regras de entrada na brincadeira e de uso dos brinquedos, dominando aos poucos os protocolos de brincadeiras e os pactos estabelecidos e conhecimentos compartilhados pelo grupo.

Nesse espaço-tempo do brincar, passado, presente e futuro interligam-se nas brincadeiras que se repetem, mas que se recriam a cada vez que se repetem, proporcionando novas possibilidades de brincar e, assim, também novas possibilidades de agir sobre o mundo. Aqui também há de se observar que o tempo recursivo da infância no plano sincrônico é fartamente utilizado nos videogames, na medida em que os jogos oferecem a possibilidade contínua de recriação das mesmas situações e rotinas, em que elas podem "morrer" e "voltar" infinitas vezes para o jogo. Enquanto que no plano diacrônico, a difusão das novas formas de brincar com os dispositivos digitais parece estar apenas se iniciando.

\section{REFLEXÕES SOBRE BRINCAR E JOGAR NA CONTEMPORANEIDADE}

Nas análises aqui apresentadas, percebe-se a importância de compreendermos que relações e significados as crianças têm tecido a partir da experiência com os videogames. Suas falas apontam para a diversão como um princípio básico que caracteriza o brincar, justificando, assim, o videogame como uma brincadeira. Entretanto, suas negativas, e dos adultos que as cercam, também 


\section{Atos de Pesquisa em Educação - ISSN 1809-0354}

Blumenau, v. 12, n.3, p.828-853, set./dez. 2017

DOI: http://dx.doi.org/10.7867/1809-0354.2017v12n3p828-853

dizem muito sobre as dificuldades para compreender o potencial lúdico dos videogames.

Assim como todas as atividades da criança, jogar videogame está sempre limitado pelo adulto, que define o que, quando e onde a criança joga. Os brinquedos também propõem alternativas, mas, no final, são as crianças que decidem, no contexto das transmissões socioculturais que estão sujeitos, como elas vão se envolver com seus brinquedos.

Perceber que a brincadeira das crianças diante dos videogames segue eixos estruturantes das culturas da infância (SARMENTO, 2004) tem potencial para nos fazer voltar o olhar para essa forma de brincar contemporânea, com toda a vitalidade da brincadeira das crianças, deixando de lado alguns preconceitos adultos quanto ao significado da tecnologia na vida das crianças.

Por isso, acreditamos que ao negarem que jogar videogame seja uma brincadeira, justificado principalmente por uma "não realidade" intrínseca nos videogames, as crianças parecem mostrar-nos muito mais uma dificuldade dos adultos em compreender os novos aspectos dessa cultura lúdica digital que pode ser sintetizada em uma frase bastante ouvida pelas crianças hoje: "Desliga esse videogame e vai brincar!"

\section{CARLA CRISTIANE LOUREIRO}

Professora dos anos iniciais do Colégio de Aplicação da Universidade Federal de Santa Catarina - UFSC.

\section{GEOVANA MENDONÇA LUNARDI MENDES}

Professora Permanente do Programa de Pós-Graduação da Universidade Estadual de Santa Catarina - UDESC. Coordenadora do projeto "Tablets, Computadores e Laptops" OBEDUC/CAPES.

\section{REFERÊNCIAS}

BENJAMIN, W. Reflexões sobre o brinquedo, a criança e a educação. São Paulo: Editora 34, 2002. 


\section{Atos de Pesquisa em Educação - ISSN 1809-0354 \\ Blumenau, v. 12, n.3, p.828-853, set./dez. 2017 \\ DOI: http://dx.doi.org/10.7867/1809-0354.2017v12n3p828-853}

BRAILOVSKY, D. La escuela y las cosas. Rosario: Homosapiens, 2012.

BROUGÈRE, G. Brinquedos e companhia. São Paulo: Cortes, 2004.

A criança e a cultura lúdica. Revista da Faculdade de Educação, São Paulo, v. 24, n. 2, p. 103-116, jul./dez. 1998.

BUCKINGHAM, D. La infancia materialista: crecer en la cultura consumista. Madrid: Morata, 2013.

. Cultura digital, educação midiática e o lugar da escolarização. Educação \& Realidade, Porto Alegre, v. 35, n. 3, p. 37-58, set./dez. 2010.

. Crescer na era das mídias eletrônicas. São Paulo: Edições Loyola, 2007.

CANCLINI, N. G. Culturas híbridas: estratégias para entrar e sair da modernidade. Tradução Ana Regina Lessa e Heloísa Pezza Cintrão. São Paulo: EDUSP, 1997.

CORSARO, W. A. Sociologia da infância. Tradução Lia Gabriele Regius Reis. Porto Alegre: Artmed, 2011.

FAJARDO, J. A. P. "El lujo de aburrirlos". Perspectivas sobre los vínculos entre videojuegos y escuela, del diseño al aula. 2015. 127 f. Dissertação (Mestrado em Ciências Socias com orientação em Educação) - Facultad Latinoamericana de Ciencias Sociales, Buenos Aires, 2015.

GRAUE, E.; WALSH, D. Investigação etnográfica com crianças: teorias, métodos e ética. Lisboa: Fundação Calouste Gulbenkia, 2003.

KISHIMOTO, T. O jogo e a educação infantil. In: KISHIMOTO, T. M. (Org.). Jogo, brinquedo, brincadeira e educação. 3. ed. São Paulo: Cortez, 1999. p.13-34.

PEREIRA, R. R. Entre o (en)canto e o silêncio das sereias: sobre o (não)lugar da criança na cibercultura. Childhood \& Philosophy, Rio de Janeiro, v. 9, n. 18, p. 319343, jul./dez. 2013.

PETERS, L. L. Jogos eletrônicos e brinquedotecas escolares: estudo de caso e análises comparativas entre Brasil e França. Relatório do estágio pós-doutoral. Colégio de Aplicação, Universidade Federal de Santa Catarina, Florianópolis, Mimeo, 2014. 


\section{Atos de Pesquisa em Educação - ISSN 1809-0354}

Blumenau, v. 12, n.3, p.828-853, set./dez. 2017

DOI: http://dx.doi.org/10.7867/1809-0354.2017v12n3p828-853

SARMENTO, M. J. A reinvenção do ofício de criança e aluno. Atos de Pesquisa em Educação, FURB, Blumenau, v. 6, p. 581-602, set./dez. 2011.

As culturas da infância nas encruzilhadas da segunda modernidade. In: SARMENTO, Manuel Jacinto; CERISARA, Ana Beatriz. (Orgs.): Crianças e miúdos: perspectivas sociopedagógicas da infância e educação. Porto: ASA, 2004. p. 9-34.

SIROTA, R. Emergência de uma sociologia da infância: evolução do objeto e do olhar. Cadernos de Pesquisa, São Paulo, n. 112, p. 7- 31, mar. 2001.

STEINBERG, S. R.; KINCHELOE, J. L. Cultura infantil: a construção corporativa da infância. Rio de Janeiro: Civilização Brasileira, 2001.

WILLIANS, R. Cultura. Rio de Janeiro: Paz e Terra, 1992. 